\title{
Aproximaciones legales y jurisprudenciales a la prueba de oficio, en el procedimiento penal adversarial con tendencia acusatoria en el ordenamiento colombiano
}

\author{
Jimmy Patiño García* \\ Gabriel Alberto Ospina Herrera ${ }^{\text {*** }}$ \\ Isabel Indira Molina Ariza ${ }^{* * * *}$
}

Resumen. El presente documento tiene como propósito efectuar una aproximación, desde el punto de vista jurisprudencial y legal, del desarrollo que ha tenido la prueba oficiosa en el sistema penal adversarial de tendencia acusatoria, implementado en Colombia con la Ley 906 de 2004, a fin de establecer la tensión existente entre los principios de imparcialidad, igualdad de armas y legalidad, frente al principio de justicia material y en el contexto del rol del juez en el proceso.

En efecto, esta es una de las discusiones que enfrentan quienes administran justicia y quienes acuden a ella para resolver los conflictos sociales, en la que se evidencia que la construcción de un sistema acusatorio es un proceso inacabado y en constante evolución. Para ello se hace necesario abordar no solo un concepto meramente legalista, sino que se requiere recabar en la filosofía misma del sistema penal acusatorio y las realidades en que este se aplica, para cumplir los cometidos sociales para los cuales fue creado.

Palabras claves: Prueba, oficio, adversarial, acusatorio, imparcialidad, legalidad.

\section{Introducción}

\footnotetext{
* Abogado, especialista en Derecho Penal de la Universidad de Ibagué.

** Abogado, especialista en Derecho Penal de la Universidad de Ibagué.

*** Abogada, especialista en Derecho Penal de la Universidad de Ibagué.
} 
El Acto Legislativo 03 de 2002, que modificó los artículos 116, 250 y 251 de la Constitución Política colombiana, dio vida a un nuevo modelo de enjuiciamiento de corte acusatorio desarrollado en la Ley 906 de 2004. En dicho procedimiento, se le prohibió de manera expresa al juez de conocimiento, decretar pruebas de oficio (art. 361 del Código de Procedimiento Penal CPP).

Este ensayo busca exponer las razones por las cuales la prohibición mencionada pone en tensión los principios de legalidad, imparcialidad e igualdad de armas, frente al principio de justicia material, en la medida en que le impone al juez de conocimiento del proceso penal, la asunción de un rol pasivo y, en esas circunstancias, pueden verse sacrificados otros principios que hacen parte de la estructura dogmática de la Constitución Política, como el de justicia material.

Para ello, desarrollaremos los aspectos doctrinales, legales y jurisprudenciales, que sobre este aspecto han sido identificados, a fin de establecer cómo se ha resuelto la tensión de principios y valores de este sistema procesal $\mathrm{y}$, particularmente, el abordaje que han efectuado frente a este tema la Sala de Casación Penal de la Corte Suprema de Justicia y la Corte Constitucional.

\section{La prueba de oficio en el Sistema Penal Acusatorio. Aproximaciones conceptuales}

\section{1. ¿Qué es la prueba?}

La prueba es el instrumento o herramienta por medio de la cual se logra el conocimiento de unos hechos con trascendencia jurídica, que luego de ser confrontados con las normas del caso, se logra el convencimiento al juez para el proferimiento de una decisión de fondo, con el fin de reconocer o no un derecho, imponer una sanción o una pena, o absolver al acusado, enjuiciado o procesado.

En el sistema penal acusatorio se han delimitado diferencias entre el debido proceso general y el debido proceso probatorio. El primero se refiere a la garantía constitucional, que de acuerdo con González Navarro (2011):

...se relaciona con la sucesión compuesta, escalonada y consecutiva de los actos regulados en la ley procesal, cuyo objeto, en materia penal, es la verificación de la conducta punible y la consecuente responsabilidad del imputado, orientados dichos actos a obtener una decisión válida y con fuerza de cosa juzgada acerca de los mismos temas, de suerte que transgredir el proceso como es debido, significa ni más ni menos, que pretermitir un acto procesal expresamente señalado en la ley como requisito sine qua non para la eficacia del subsiguiente ... (p. 14) 
Por su parte, el debido proceso probatorio, de acuerdo con González Navarro (2011) “....atañe al conjunto de requisitos y formalidades previstas en la ley para la formación, validez y eficacia de la prueba" (p. 15). De la misma manera "...debe sujetarse a principios basilares, como son la legalidad, publicidad, oralidad, contradicción, inmediación y concentración, so pena de desnaturalizar el respectivo acto probatorio..." (p.15).

En efecto, el debido proceso probatorio es, de manera específica, el ámbito del derecho procesal que articula los procedimientos y ritualidades que reglan los procedimientos para la aducción de la prueba, con los principios constitucionales y legales que sustentan el sistema penal acusatorio.

\section{2. ¿Qué es la prueba de oficio? Desarrollo legal en Colombia}

La prueba de oficio apunta, de manera genérica, a la facultad que tiene el juez para decretar y practicar pruebas en el proceso, a efectos de poseer mayores elementos de juicio que le permitan dilucidar el asunto por resolver.

Específicamente, la prueba de oficio está instituida en nuestro ordenamiento jurídico en las áreas del Derecho Procesal Constitucional (hábeas corpus, acción de tutela, acción de cumplimiento, acciones populares y de grupo) en las áreas civil, laboral, familia, administrativo y en el procedimiento penal previsto en la Ley 600 de 2000.

Así, el Código General del Proceso refiere, en su artículo 167, que, en principio, "incumbe a las partes probar el supuesto de hecho que las normas que consagran el efecto jurídico que ellas persiguen", empero, el inciso siguiente de la norma en mención, indica que en determinados casos, el juez puede distribuirla — carga dinámica de la prueba - y en los artículos 169 y 179, ibídem, señala que el juez puede decretarla de oficio y reseña algunas reglas de procedibilidad con respecto a ella, como que su necesidad debe estar sujeta a que se verifiquen los hechos planteados en los alegatos de las partes, que quienes sean llamados como testigos deben necesariamente aparecer en otras, o en cualquier acto procesal de las partes y que debe ser decretada en las oportunidades probatorias.

En el mismo sentido, el Código de Procedimiento Administrativo y de lo Contencioso Administrativo prescribe, en el artículo 180, entre otras reglas, que el juez puede decretar pruebas de oficio para esclarecer los hechos y, en igual sentido, el Código de Procedimiento Laboral, refiere dicha potestad en el artículo 54.

Por su parte, el Código de Procedimiento Penal de corte inquisitivo, instituido en la Ley 600 de 2000, señala en el artículo 234, la posibilidad de que 
el juez decrete pruebas de oficio. Y, por último, el Código de Procedimiento Penal de tendencia acusatoria implementado a través de la Ley 906 de 2004, en su artículo 361, prohíbe taxativamente al juez de conocimiento decretar pruebas de oficio.

\section{3. ¿Cuál es el procedimiento para el descubrimiento, decreto, presentación, incorporación y aducción de pruebas?}

De manera genérica debe decirse que las pruebas son decretadas en la etapa procesal que la ley establece para ello. En cuanto a la parte demandante, esta realiza su solicitud en la demanda, al reformar la misma, al momento de contestar las excepciones o demanda de reconvención propuesta por el demandado, con la limitante de que estas pruebas solo se deben referir a los asuntos de las excepciones de la reconvención. A su turno, la parte demandada concibe sus solicitudes probatorias junto con la contestación a la demanda, en la demanda de reconvención, con las excepciones que propone y al igual que el demandante, dentro de los trámites incidentales del proceso.

En el esquema adversarial del Sistema Penal Acusatorio, se tiene que solo son pruebas aquellas decretadas en la audiencia preparatoria, recaudadas en el juicio y con la observancia del debido proceso, las garantías fundamentales y los principios de legalidad, publicidad, oralidad, contradicción, inmediación y concentración. Lo anterior no obsta para indicar que el juez de Control de Garantías, como juez constitucional, posee amplias facultades para ordenar medios de conocimiento en desarrollo de las audiencias preliminares de control de garantías.

La Fiscalía General de Nación dispone de varias etapas para el descubrimiento de sus elementos materiales probatorios, evidencia física e información legalmente obtenida. La primera etapa se realiza ante el juez de Control de Garantías, en desarrollo de las audiencias preliminares y, en particular, aquellas que requieren de la verificación de los medios de conocimiento (denominados así, al no tener la calidad de pruebas en el proceso penal), que permitan establecer una inferencia razonable de autoría, participación en el hecho investigado, a efecto de tramitar audiencias preliminares como las de legalización de captura y de solicitud de medida de aseguramiento. La segunda se cumple en la formulación de acusación, cuando la Fiscalía debe descubrir los elementos de conocimiento que la defensa solicite sin perjuicio de que, desde la presentación del escrito de acusación y por conducto del juez, el fiscal tenga la obligación de suministrar todos los elementos probatorios e informaciones de los cuales tenga noticia, incluidos aquellos que le sean favorables al procesado. Y, por 
último, en la audiencia preparatoria, la defensa debe haber tenido pleno acceso a los elementos materiales probatorios, evidencia física e información legalmente obtenida por la Fiscalía.

En la audiencia de formulación de acusación, el juez debe ordenar a la defensa que entregue copia a la Fiscalía de los elementos de conocimiento con que cuente, de acuerdo con su solicitud, pero el descubrimiento probatorio de la defensa se hace de manera completa en la audiencia preparatoria e, igualmente, el Ministerio Público puede realizar solicitudes probatorias en esta audiencia. Debe acotarse que existen otros institutos procesales probatorios, que permiten de manera excepcional, descubrir y decretar solicitudes de prueba fuera de los escenarios ya indicados, como la prueba sobreviniente.

Ahora bien, la asunción del procedimiento penal abreviado implica que el descubrimiento probatorio de la Fiscalía —obligación que adquiere el acusador privado - debe realizarse en el traslado del escrito de acusación y la defensa efectuará su descubrimiento probatorio en la audiencia concentrada.

Así las cosas, el procedimiento penal adversarial ha asignado de manera concreta a las partes, es decir, Fiscalía (acusador privado si fuere el caso), defensa y al Ministerio Público, la función de realizar las solicitudes probatorias, descubrimiento probatorio y aducción de las pruebas en juicio oral.

\section{4. ¿Cuáles son las características de la prueba de oficio?}

Las pruebas de oficio tienen las siguientes características:

i. Tienen fundamento en principios de orden constitucional y legal.

ii. Son admisibles en áreas del Derecho Procesal Constitucional, Procesal Civil y Familia, Procesal Laboral, Procesal Administrativo y la Ley 600 de 2000 .

iii. Gozan, igualmente, del régimen de libertad probatoria, como sucede con las pruebas solicitadas por las partes.

iv. Las pruebas de oficio se rigen por el principio de permanencia de la prueba.

v. En la Ley 906 de 2004, el juez de Control de Garantías tiene la facultad de decretarlas.

vi. El Código de Procedimiento Penal actual prohíbe taxativamente al juez de conocimiento el decreto y práctica de pruebas de oficio.

vii. El recaudo probatorio se encuentra reglado por el debido proceso constitucional y el debido proceso probatorio de la Ley 906 de 2004.

viii. En la ley 906 de 2004 la prueba se rige por el principio de inmediación. 


\subsection{Pruebas en el Proceso Penal colombiano}

\subsubsection{Las pruebas en la Ley 600 de 2000}

El procedimiento de la Ley 600 de 2000, se caracteriza por ser de corte inquisitivo y escrito, a través del cual la Fiscalía ejerce amplias funciones jurisdiccionales, con las cuales investiga, acusa e instruye el proceso; es decir, desarrolla funciones de investigación, acusación y juzgamiento.

En la Ley 600 de 2000, tanto en la etapa de instrucción como en la de juzgamiento, se pueden solicitar y practicar pruebas, la cuales gozan del principio de permanencia, fenómeno que se encuentra ligado a la naturaleza escritural del procedimiento. La carga de la prueba de la conducta punible y de la responsabilidad del procesado, corresponde directamente a la Fiscalía General de la Nación; además, señala que el juez puede decretar pruebas de oficio.

\subsubsection{En la Ley 906 de 2004}

Se caracteriza por ser un sistema oral y es la intervención de las partes la que determina el contenido del proceso, por ser adversarial y de tendencia acusatoria. En este caso existe división de funciones entre quien investiga y acusa y el funcionario que juzga. El fiscal es el director de la investigación, con funciones jurisdiccionales excepcionales, como las que ejerce en los procedimientos de captura.

Su naturaleza adversarial, o de partes, contiene el principio de igualdad de armas de la Fiscalía y la defensa, que implica en el plano normativo, equidad de condiciones y las mismas posibilidades en materia investigativa y probatoria. En la Ley 906 de 2004, solo se pueden tener por pruebas aquellas que se practican en presencia del juez de conocimiento, atendiendo el principio de inmediación, y, solo por vía excepcional, se admiten pruebas aducidas de manera distinta a la señalada, como las de referencia o la anticipada.

El artículo 372 del Código de Procedimiento Penal prevé que la finalidad de las pruebas es llevar al juez al conocimiento, más allá de duda razonable, sobre los hechos y circunstancias materia del proceso y los relacionados con la responsabilidad del procesado, como autor o partícipe del delito. De tal manera, los hechos y circunstancias de interés para la solución correcta del caso, se podrán probar por cualquiera de los medios establecidos en el código o por cualquier otro medio técnico o científico, siempre y cuando se observen las garantías y derechos constitucionales y legales para su aducción.

En este sistema se destacan los principios de concentración, inmediación, contradicción, publicidad y, de manera primordial, el de imparcialidad, que le 
impone al juez de conocimiento que en ningún caso podrá decretar la práctica de pruebas de oficio, para evitar que sustituyera a una de las partes en su deber procesal, pues obrar de forma contraria haría que el juez se parcializara y al hacerlo rompería el equilibrio propio del proceso, puesto que cuando este ordena y práctica una prueba, necesariamente se tendría que favorecer a una de las partes e ir en detrimento de la otra. Así, la hipótesis frente a la imposibilidad de decretar pruebas de oficio refiere principalmente, que actuar de modo contrario, socavaría los postulados propios del debido proceso, como fue decantado por la Corte Constitucional, que se encargó de declarar la exequibilidad del artículo 361 del CPP, que prohíbe las pruebas de oficio (Corte Constitucional, Sentencia C-396 de 2007).

\section{Desarrollo jurisprudencial sobre la prueba de oficio en la Corte Constitucional y la Sala Penal de la Corte Suprema de Justicia \\ 2.1. Justificación y aproximación metodológica}

La construcción de una línea jurisprudencial se ha consolidado como un instrumento eficaz para los operadores judiciales, porque permite a través del rastreo metódico de la jurisprudencia, la solución de un problema práctico en la labor jurídica, y por ello su construcción debe estar íntimamente vinculada con la solución de un caso específico.

Esta propuesta de trabajo fue desarrollada en Colombia por el profesor Diego López Medina y presentada en el libro El Derecho de los jueces, en medio de la discusión sobre la fuerza vinculante del precedente judicial y la necesidad de superar el mero legalismo, a lo cual se contrapone la necesidad de aplicar normas de principio y su estructura axiológica. En consecuencia, se admite el concepto de derecho viviente, esto es, el derecho manifestado en las sentencias, el que se materializa en la vida real de las personas.

En efecto, el artículo 361 del Código de Procedimiento Penal prohíbe de manera expresa al juzgador decretar pruebas de oficio; pero la jurisprudencia ha desarrollado algunos matices a esta postura en situaciones excepcionales; razón por la cual nos permitiremos desglosarla a través de la propuesta metodológica del profesor Diego López Medina.

El problema jurídico relevante con miras a revisar su desarrollo jurisprudencial consiste en establecer, ¿le es permitido de manera excepcional al juez penal de conocimiento, el decreto de pruebas de oficio, en el sistema acusatorio con tendencia adversarial? O de manera más genérica, en el sistema procesal penal adversarial con tendencia acusatoria que rige en Colombia, ¿cómo ha 
resuelto la jurisprudencia colombiana la tensión entre el principio de imparcialidad, de igualdad de armas y de legalidad, frente al principio de justicia material, cuando se trata del rol que debe asumir el juez frente al decreto de pruebas de oficio, en las audiencias de conocimiento?

\subsection{Patrón fáctico de la Sentencia arquimédica y tesis que se desarrollan en la línea jurisprudencial}

La sentencia seleccionada como arquimédica ${ }^{4}$ expone el caso en el que el representante legal de las víctimas presentó recurso de casación, en el proceso que investigó la presunta comisión de unas lesiones personales en la modalidad culposa, e indica el casacionista, entre otras razones para recurrir en casación la decisión absolutoria, que el juez debió haber suplido la falencia del ente acusador y decretado pruebas de oficio. La Corte, en este caso, reseña que el juez no puede determinarlas; primero, porque dicha práctica se encuentra proscrita del ordenamiento jurídico, segundo, por la naturaleza eminentemente adversarial del proceso y, tercero, el principio de igualdad de armas (Corte Suprema de Justicia-Sala de Casación Penal, Sentencia Radicado $\mathrm{N}^{\circ} .47 .212$ de 2016).

En esta misma línea, se circunscribe el auto que inadmite la demanda de casación contra la sentencia condenatoria a un ciudadano por el delito acceso carnal violento, en la que el defensor casacionista manifiesta que el defensor de instancia incurrió en grave yerro, el cual vulneró el derecho de defensa y las garantías fundamentales del procesado, al no solicitar la práctica de una prueba genética; por cuanto la Fiscalía verificó que no le era favorable y desistió de ella, y el juez de conocimiento la ordenó para beneficio de la defensa, sin que el defensor la hubiera solicitado en la audiencia preparatoria, decisión que fue apelada por la Fiscalía y revocada en segunda instancia.

En este caso, la Sala Penal de la Corte señala que la actividad oficiosa del juzgador se encuentra proscrita del ordenamiento jurídico, y concluyó que no se afectó derecho fundamental alguno, porque entre otras cosas, la parte supuestamente afectada con su exclusión la conocía previamente (Corte Suprema de Justicia-Sala de Casación Penal, Sentencia Radicado Nº 45.699 de 2015).

\footnotetext{
${ }^{4}$ La estructura metodológica del análisis jurisprudencial propuesto por el profesor Diego López Medina requiere, en primera instancia, hallar una sentencia llamada "sentencia arquimédica", que debe tener como característica ser muy reciente y responder a un problema jurídico de interés. Los textos base de la metodología descrita son: López Medina, D. E. (2009). El Derecho de los jueces, Bogotá, Colombia: Editorial Legis., y López Medina, D. (2006). Interpretación constitucional. Bogotá, Colombia: Universidad Nacional de Colombia.
} 
Esta ha sido la línea jurisprudencial dominante en la Corte Suprema de Justicia, cuando ha tramitado recursos de casación y se han ventilado procesos de la jurisdicción ordinaria en delitos comunes. Sin embargo, a estos mismos argumentos - esencialmente referidos a que la prohibición proveniente de la norma procesal penal, proscribe la actuación oficiosa frente a la prueba, y otorga relevancia a la aplicación de los principios de igualdad de armas, imparcialidad y el de legalidad - no se les asignó el mismo peso, cuando se trata de delitos que constituyen violaciones al derecho internacional humanitario y a los derechos humanos.

Es así que en la Sentencia 31091 de 2010 de la Corte Suprema de JusticiaSala Penal, que decide el recurso de reposición contra el auto que negó la práctica de las pruebas de la defensa y que decretó pruebas de oficio, se indicó que por la connotación especial del proceso sometido a conocimiento, puede inaplicar prohibiciones que en determinadas condiciones no son de naturaleza absoluta porque está de por medio el interés público en que se investiguen los delitos, se reconstruya la verdad para conocerla, se sancione a los responsables y se indemnice a las víctimas. Enfatiza en esta decisión, el rol del juez y le otorga especial relevancia como promotor de los cometidos del Estado social, democrático y de derecho, el cumplimiento de los fines constitucionales del proceso penal, entre los que cuenta el valor de la justicia material dentro de un marco jurídico.

Para dar peso argumentativo a esa postura, desarrolla los lineamientos contenidos en lo expuesto por la Corte Suprema de Justicia-Sala de Casación Penal, en la Sentencia 14464 de 2005, que se refiere específicamente al alcance del principio-regla de la prohibición de reforma en perjuicio reformatio in pejus. Dicha sentencia indica que el juez no es un mero espectador, que debe alcanzar la verdad histórica objetiva, evento en el cual se concreta la justicia material.

La siguiente sentencia puede ser considerada como la fundadora de la línea jurisprudencial que admite la prueba de oficio de manera excepcional, y ella se encarga de desatar un recurso de casación sobre un fallo que, en sede de segunda instancia, condenó a un ciudadano por el delito de actos sexuales con menor de catorce años, agravado por ser menor de doce años, y que durante el desarrollo del juicio oral el juez de conocimiento decretó, por solicitud de la Fiscalía y del representante legal de la víctima, el testimonio de la niña; solicitud probatoria que no fue descubierta en la audiencia de formulación de acusación, ni enunciada por las partes en la audiencia preparatoria (Corte Suprema de Justicia-Sala de Casación Penal, Sentencia Radicado N .24468 de 2006). 
Esta decisión se destaca porque dedica un análisis sistemático de la norma que prohíbe el decreto de pruebas oficiosas en el sistema penal acusatorio, bajo tres líneas argumentativas. La primera tiene que ver con aquello que ya había sido reseñado por la Corte Constitucional (Sentencia C-591 de 2005), con relación a que los nuevos parámetros del Acto Legislativo No. 03 de 2002, que se introdujeron en la Constitución Política, deben guardar armonía con los principios generales y los derechos fundamentales de la Carta Política, teniendo en cuenta que las modificaciones introducidas por él, afectaron la parte orgánica y no la parte dogmática de aquella.

La segunda desarrolla la cuestión del rango constitucional de las víctimas en el proceso penal, y como parte activa en este, conforme al Acto Legislativo 3 de 2002, el cual indica que las víctimas tienen intereses directos en la verdad, la justicia y la reparación.

La tercera esclarece los argumentos del rol del juez en el proceso penal adversarial con tendencia acusatoria, e indica que, en desarrollo del principio de imparcialidad, los actos de investigación en el proceso penal fueron separados de los actos de conocimiento. Sin embargo, a renglón seguido, aduce que el rol del juez no es el de un simple árbitro y, por tanto, de manera excepcional, a fin de brindar aplicación a los postulados de orden constitucional, y la concreción de los fines del Estado, como la aplicación de una justicia material, el respeto a los derechos fundamentales del procesado y de la víctima, puede el juez inaplicar una norma de orden legal. Para ello resulta necesario que sea él quien argumente razonablemente frente a cada caso concreto, la razón por la cual la restricción sobre el decreto de pruebas de oficio, produce efectos incompatibles con los postulados constitucionales.

Sin embargo, en este caso fue precisamente la Corte quien advirtió que el juez de conocimiento, al resolver la admisión de esta prueba, incurrió en una argumentación que denomina "liviana", dado que el juez no motivó suficientemente las razones por las cuales la admitió, pero advirtió que en este caso, quien había presentado la carga argumentativa suficiente y necesaria para aceptarla, fue el Ministerio Público, que coadyuvó su solicitud y posibilitó su decreto oficioso por parte del juez, sin que esa admisión probatoria se encuentre viciada de ilegalidad.

No puede dejarse de analizar la sentencia que declara la exequibilidad del artículo 361 de la Ley 906 de 2004 (Corte Constitucional, Sentencia C-396 de 2007). Esta decisión es muy importante, ya que aborda la prohibición de decreto de pruebas de oficio por parte del juez de conocimiento, desde la perspectiva 
de la coherencia con el modelo de enjuiciamiento acusatorio propio y de las garantías constitucionales de las partes.

Esta sentencia, termina otorgando mayor relevancia a la integridad del modelo acusatorio, señalando en concreto que, aunque en otras latitudes geográficas ese modelo no riñe con el decreto excepcional y oficioso de pruebas por el juez de conocimiento, Colombia no está obligada a adoptarlos, refiriendo que incluso, el legislador goza de un amplio margen de configuración en dichas materias; enseña que la igualdad de armas del procedimiento acusatorio es la concreción del derecho al debido proceso y a la equidad de trato, y que la medida prohibitiva es legítima, en tanto busca evitar el riesgo de la supremacía de una parte frente a otra, y aunque admite que en el procedimiento acusatorio existe una clara desigualdad institucional, por la ventaja de la Fiscalía en términos de fortaleza investigativa, económica, orgánica y funcional, frente a la defensa, esta situación se equilibra por la aplicación de principios procesales como la presunción de inocencia y el in dubio pro reo.

Refiere que el principio de imparcialidad se concreta en el proceso penal, a través de la neutralidad probatoria del juez y que esa pasividad es una garantía del acusado. Indica que la prohibición del decreto y práctica oficiosa de pruebas hace parte de la estructura del sistema penal acusatorio y es un principio procesal dirigido a determinar el rol de los intervinientes en el proceso penal y, de otro, debe entenderse como una garantía sustancial de eficacia del deber del Estado de aproximarse a la verdad de lo sucedido, dentro de los parámetros señalados por las garantías y libertades individuales de orden constitucional y legal.

Advierte que no es correcto ligar la búsqueda de la verdad con el decreto oficioso de pruebas, porque dicha regla probatoria debe mirarse en contexto y desde la finalidad que se busca con ella. Aduce que cuando hay deficiencia en la investigación o la actitud de la defensa es pasiva por estrategia o por defecto, se considera que la restricción de la prueba de oficio puede afectar la consecución de la verdad real. Admite, igualmente, que el solo decreto de una prueba no tiene necesariamente el efecto de buscar una condena o absolución, o que el juez se ubique en la posición de una parte, pero advierte que dicho argumento no es tan fuerte en la medida en que indica “... no se trata de avalar el abandono de la búsqueda de la verdad, se trata de acercar el proceso penal a las garantías de la democracia constitucional y en este sentido entender el concepto de verdad..." (Corte Constitucional, Sentencia C-396 de 2007). Y porque considera que se están llenando vacíos probatorios con la intervención activa del juez y esa situación desequilibra la posición de las partes. 
Esta decisión mayoritaria no fue compartida por el magistrado Nilson Pinilla Pinilla, quien salvó su voto, indicando que el juez penal debe, de manera excepcional, ostentar la posibilidad de decretar pruebas de oficio, por cuanto los jueces deben buscar la verdad, hacer prevalecer el derecho sustancial y procurar la defensa y eficacia de los derechos constitucionales. Señala que resulta contradictorio que en otras ramas del Derecho se permita el decreto de pruebas oficiosas y que con ello no se afecta la neutralidad, y que, en el Derecho Penal, más garantista, no se permita esta atribución.

Indica el magistrado disidente, que esta facultad (la de decretar pruebas de oficio), es excepcionalísima, que sirve para superar aspectos que no permiten arribar a la verdad real; que no puede interferir o suplir la iniciativa de las partes. Refiere que son principios generales del derecho la verdad, la justicia y la reparación; que la impunidad es una infracción a los deberes del Estado y que esas obligaciones se encuentran contenidas en instrumentos internacionales. Aduce que, con fundamento en la Sentencia de constitucionalidad C-591 (Corte Constitucional, 2005) que señaló, entre otras cosas, que el juez no es un mero árbitro del proceso, la misma Corte Constitucional se está apartando de su propio criterio interpretativo, porque si en dicha decisión se le otorga al juez la obligación de esclarecer la verdad en procura de la justicia material, debe estar facultado excepcionalmente para decretar pruebas de oficio.

Refiere, igualmente, que, en múltiples decisiones, la Corte Constitucional ha concedido relevancia al derecho a la verdad y a la justicia, como valor fundamental que, además, conlleva al respeto hacia la dignidad humana, el cual no cobija exclusivamente a la víctima, a su familia y a la sociedad, pues incluye al procesado. Señala que la prohibición de la prueba oficiosa se debe en parte, al culto de sistemas foráneos; que el decreto de estas no afecta el principio de imparcialidad; que incluso en algunos sistemas penales acusatorios se admite la prueba de oficio y, además, la prueba aún si es oficiosa debe mantener su legalidad, publicidad, y debe respetarse su contradicción. Concluye que el juez administra justicia y un juez que no absuelve las dudas, no puede cumplir con el cometido social y, la prohibición absoluta, es contraria a las normas constitucionales. En este sentido enfatiza el cometido constitucional que se busca concretar con la prueba de oficio y, anticipa, cuál sería el procedimiento para la aducción de una prueba de este tipo, al advertir que el juez no puede incluir las pruebas que a bien tenga en la audiencia preparatoria, sino que dicho decreto deberá producirse una vez se ha agotado el juicio oral (Corte Suprema de Justicia-Sala Penal, Sentencia Radicado N .24 .468 de 2006). 
Aun cuando la siguiente decisión que abordaremos no resuelve en sentido estricto los problemas jurídicos enunciados, resulta necesaria traerla a colación, porque analiza algunos principios que permiten resolver los problemas planteados - tuvo salvamentos de voto, y es muy reciente-. Estas características indican que en la actualidad se presentan opiniones encontradas frente a esos temas, de modo que permite entender las diferentes posturas que existen hoy día; igualmente, cómo las decisiones que proscriben la prueba oficiosa apelan a la enunciación normativa que expresamente la prohíbe, no aparecen argumentos elaborados frente a los tópicos que se plantean en la tesis contraria, situación que en este caso se invierte, por cuanto la tesis ganadora inaplica una norma de orden legal y amplifica, por decirlo de algún modo, el rol del juez. Por último, se atiende su importancia por cuanto uno de los salvamentos de voto, refiere de manera específica su postura sobre la oficiosidad de la prueba, como argumentos para sustentar sus tesis.

Se trata de la Sentencia 43837 de 2016 (Corte Suprema de Justicia-Sala de Casación Penal), en la cual se decide el recurso de casación, que la defensa del procesado interpuso, por la sentencia condenatoria que el juez de segunda instancia profiriera, por el delito de actos sexuales abusivos con menor de catorce años, a pesar de que el fiscal solicitó en su alegación final la absolución.

La Sala Penal de la Corte Suprema, en este caso, consideró que la petición de absolución no obliga al juez de conocimiento, y dispuso decretar la nulidad de lo actuado, desde la actividad subsiguiente a la alegación final del ente acusador, al considerar que se profirió la decisión de absolver al procesado conforme con lo solicitado por el fiscal, sin la motivación necesaria.

Frente a dicha postura nos centraremos en recabar los argumentos que, de manera directa, tienen incidencia en nuestro problema jurídico, dejando de lado un poco los aspectos centrales frente a la petición de absolución de la Fiscalía, tema que desborda el objeto de nuestro estudio.

En efecto, dicha decisión aborda varios elementos de discusión, el primero de ellos, frente a la estructura del proceso penal y advierte que el sistema penal acusatorio colombiano, no es netamente adversarial, porque se tiene permitido otros actores en el proceso penal, que además gozan de facultades procesales y esas particularidades impiden considerarlo un sistema puro, sino con tendencia acusatoria, razón por la cual no puede asimilarse a un sistema procesal semejante al continental europeo o al norteamericano, de acuerdo con lo señalado en la Sentencia C-591 (Corte Constitucional, 2005). 
Enfatiza que el rol del juez en el proceso penal, no se corresponde con el de un mero árbitro, y por eso debe propender por la aplicación de la justicia material, por la defensa de los derechos y garantías fundamentales de las partes e intervinientes. Y en ese contexto, aseveró que la petición de absolución de la Fiscalía es una pretensión, pero no una decisión, ya que si atara al juez de conocimiento, la decisión del juzgador no sería una providencia judicial sino "... un acto de refrendación de la discrecionalidad de la parte acusadora" (Corte Suprema de Justicia- Sala de Casación Penal, Sentencia Radicado N ${ }^{\circ} .43837$ de 2016), pero ese acto de refrendación, no constituye una decisión de fondo, por no ser una providencia dictada de manera autónoma e independiente.

Como puede observarse, la Sala Penal retoma dos argumentos que también fueron tenidos en cuenta para admitir de manera excepcional la prueba de oficio; la naturaleza especial del procedimiento penal con tendencia acusatoria y el rol del juez en el proceso penal adversarial.

El salvamento presentado por el magistrado Eugenio Fernández Carlier refiere que la decisión contraviene el principio de legalidad, previsto en el artículo 448 de la Ley 906 de 2004, y la naturaleza del sistema procesal vigente, no autoriza al juez a inaplicar normas que son coherentes con nuestro sistema penal acusatorio.

Señala que el juez no puede asumir la función acusadora que le corresponde a la Fiscalía, porque con esa postura se vulnera el principio de imparcialidad; indica, así mismo, que él no puede sustituir a las partes, o apoyar los actos que corresponden a estas y la facultad oficiosa podría dar lugar a que condene por delitos por los cuales no se ha reclamado condena o se encuentren en la acusación, razón por la cual no puede, de manera oficiosa, asumir el problema jurídico.

El salvamento presentado por los magistrados José Luis Barceló Camacho, José Francisco Acuña Vizcaya y Luis Guillermo Salazar Otero, desarrolla varias líneas de argumentación. La primera se refiere a la naturaleza del sistema procesal penal en Colombia e indica que no puede denominarse que el sistema penal es puro, sino que se cataloga como de tendencia adversarial, lo cual no desnaturaliza el hecho de que es un sistema de partes; que la modulación en la legislación colombiana del principio adversarial, de acuerdo con la Sentencia C-591 (Corte Constitucional, 2005), por la participación limitada de las víctimas y del Ministerio Público, no trastoca la filosofía que circunscribe el debate jurídico a quienes son parte. Admite la tutela judicial efectiva como derecho de las víctimas, pero enmarcado en un proceso adversarial, en el cual ellas no son parte, razón por la cual su pretensión debe ser encaminada en el 
proceso a través del fiscal y que ello no implica la desnaturalización de quien ejerce la titularidad de la acción penal.

Señala el salvamento que, frente al rol del juez en el proceso penal, el tratadista Luigi Ferrajoli en su libro Derecho y razón ha delineado cuál es el rol del juez en el sistema procesal acusatorio; que en ese escenario se parte del principio de imparcialidad y concluye que esta nueva estructura procesal despoja al juez del rol de investigador oficioso. Refiere que su función es equilibrar la actuación de las partes y, por tanto, no le asiste interés en que se gane o pierda el proceso, para uno de los contendientes. Señala que las posturas de la Corte Suprema de Justicia que le permitían un rol oficioso y, pone precisamente como ejemplo, la Sentencia 24468 (Corte Constitucional, 2006), al permitir la inaplicación por vía de excepción de inconstitucionalidad, de las normas que limitan su rol, fueron superadas y se estaba consolidando la línea jurisprudencial que confería importancia a los actos de parte.

Reseña que la nueva postura mayoritaria en esta decisión recaba una concepción que parecía superada en la línea jurisprudencial de la Corte, desborda y desquicia el papel imparcial del juez, sustituye las funciones del fiscal y auspicia una máxima de la experiencia referida a que el juez razona mejor que el fiscal, matizando lo que es esencialmente una garantía fundamental del acusado, anteponiendo los intereses de la víctima, de quien se predica que no es parte, sino interviniente.

Indica que el control judicial al aplicarse figuras como el principio de oportunidad, solicitar la preclusión, entre otras, no da lugar a que se aplique en otras actuaciones como las de petición de absolución, ya que existen actuaciones del fiscal sobre las que no se ejerce control por el juez, y tampoco puede este último sugerirle al primero que practique una prueba ni la decrete de oficio, así tenga la persuasión de que la falta de ella impide la concreción del principio de justicia material.

Concluye que la nueva tesis mayoritaria no advierte cómo afecta el principio de igualdad de armas, y promueve la concentración de poder en un solo funcionario, fenómeno que precisamente buscó evitarse con el acogimiento sistema penal acusatorio; que la decisión mayoritaria rescata modelos inquisitivos que se pretendieron superar y que debe estructurarse un sistema coordinado para construir una política criminal coherente que articule el sistema procesal actual.

Para una mejor ilustración de las tesis relacionadas, se presenta a continuación el gráfico de la línea jurisprudencial: 
Tabla 1. Esquema gráfico de la línea jurisprudencial

\begin{tabular}{|c|c|c|}
\hline $\begin{array}{l}\text { Tesis de menor } \\
\text { reconocimiento }\end{array}$ & $\begin{array}{c}\text { Distribución espacial de las sentencias según la } \\
\text { tesis que sustenta }\end{array}$ & $\begin{array}{l}\text { Tesis de máximo } \\
\text { reconocimiento }\end{array}$ \\
\hline $\begin{array}{l}\text { En el Proceso } \\
\text { Penal colombiano } \\
\text { adversarial y de } \\
\text { tendencia acusa- } \\
\text { toria, al juez de } \\
\text { conocimiento le } \\
\text { es permitido, de } \\
\text { manera excep- } \\
\text { cional, el decreto } \\
\text { de pruebas de } \\
\text { oficio, inaplicando } \\
\text { normas de orden } \\
\text { legal, a fin de dar } \\
\text { cumplimiento de } \\
\text { postulados consti- } \\
\text { tucionales, como } \\
\text { la aplicación de la } \\
\text { justicia material } \\
\text { y el respeto a los } \\
\text { derechos funda- } \\
\text { mentales. }\end{array}$ & 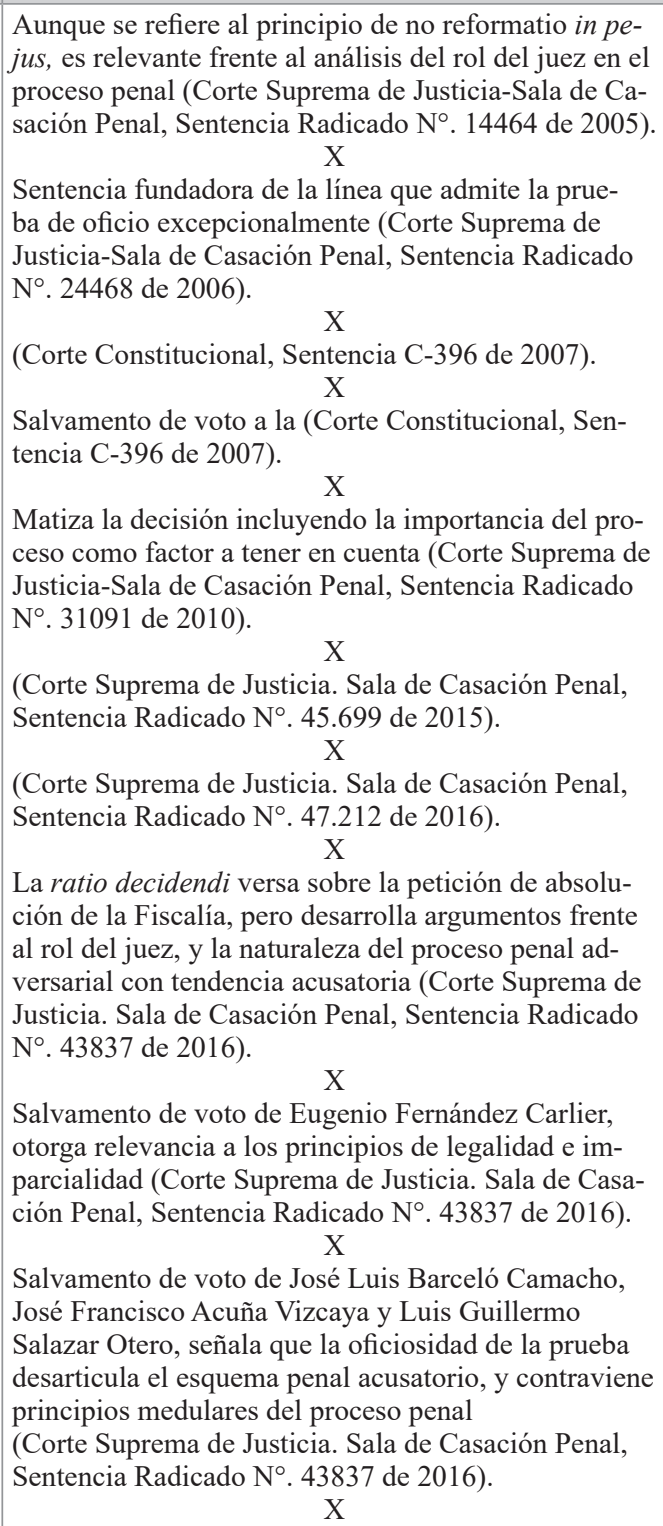 & $\begin{array}{l}\text { En el Proceso } \\
\text { Penal colombiano } \\
\text { adversarial y de } \\
\text { tendencia acu- } \\
\text { satoria, la prohi- } \\
\text { bición al juez de } \\
\text { conocimiento de } \\
\text { decretar pruebas } \\
\text { de oficio es de } \\
\text { carácter absoluta, } \\
\text { ya que se encuen- } \\
\text { tra expresamente } \\
\text { prohibida en la } \\
\text { legislación penal } \\
\text { y dicha negativa } \\
\text { pretende asegurar } \\
\text { los principios de } \\
\text { imparcialidad, } \\
\text { igualdad de armas } \\
\text { y el de actos de } \\
\text { parte. }\end{array}$ \\
\hline
\end{tabular}

Fuente: El esquema presentado hace parte de la metodología del profesor Diego López Medina. Los contenidos de este esquema son de quienes presentamos este ensayo 


\section{Resultados y discusión}

La posibilidad del decreto de pruebas oficiosas en el proceso penal, así sea de carácter excepcional, dada su prohibición normativa, pone de presente, como se dijo previamente, que el sistema procesal adversarial de corte acusatorio es un sistema inacabado, en constante evolución y que lejos de admitirse un ideal sistémico, algunos tópicos dan cuenta que es ineludible recurrir a los imperativos y garantías constitucionales y que estos se vinculen con la dinámica propia del sistema.

En efecto, los imperativos constitucionales como el derecho al debido proceso, considerado en su doble dimensión de deber-garantía, han sido tenidos en cuenta para avalar, tanto las tesis que consideran que no es admisible la prueba de oficio, como las que han estimado que es posible decretarla en el proceso penal.

Así, el debido proceso, visto desde la exequibilidad de la prohibición normativa impone una perspectiva integrista, en tanto esta se analiza bajo el tamiz de la integridad del sistema procesal acusatorio y la posibilidad de que la alteración o, más bien, la modulación excepcional de los roles de quienes intervienen en el proceso penal en el decreto de pruebas, pueda desequilibrar la balanza procesal, desestimar los actos de parte y, frente al rol del juez, socavar el principio de imparcialidad en su actuación.

Sin embargo, debe recordarse que el sistema procesal acusatorio se encuentra supeditado al sistema de principios y valores de la Carta Política, en tanto el Acto Legislativo 3 de 2002 no modificó la parte dogmática de la Constitución y, por tanto, valores como el de justicia material y la consecución de un orden justo, resultan determinantes en las actuaciones de la administración.

Cabe cuestionarse, igualmente, si realmente el principio de neutralidad probatoria y de imparcialidad del juez se podría llegar a ver perjudicado con el decreto de una prueba oficiosa, teniéndose en este caso, que la solución que plantea el salvamento de voto de la Sentencia C-396 (Corte Constitucional, 2007) es una solución plausible, por cuanto sería al terminarse la aducción probatoria de las partes en el juicio oral, el momento procesal en que el juez podría decretarla y practicarla, atendidas las circunstancias especiales del proceso y la trascendencia que esta podría tener para resolver el asunto. Dicha solución es razonable porque el juez no debe tener una teoría del caso y, por tanto, no puede de entrada en la audiencia preparatoria, por vía de ejemplo, decretar una prueba oficiosa, en tanto no puede anticipar las falencias probatorias del juicio oral.

También debe tenerse en cuenta que la prueba oficiosa sería la ultima ratio del debido proceso probatorio en la medida en que como ya se dijo, las partes 
cuentan con los instrumentos legales para hacer un debate probatorio ajustado a los cometidos constitucionales, tales como la prueba sobreviniente, la prueba de refutación, entre otras.

De tal manera, consideramos que la discusión está servida y que esta temática se presenta como excusa para debatir cómo se articulan los fines y principios del sistema penal acusatorio en el contexto del derecho viviente.

\section{Referencias}

Alvarado Velloso, A. (2006). La prueba judicial. Valencia, España: Editorial Tirant lo Blanch.

Armenta Deu, M. T. (2007). Lecciones de derecho procesal penal. Madrid, España: Marcial Pons, Ediciones Jurídicas y Sociales.

Bedoya Sierra, L. F. (2008). La prueba en el Proceso Penal Colombiano. Bogotá, Colombia: Fiscalía General de la Nación.

Cuello Iriarte, G. (2008). Derecho probatorio y pruebas penales. Bogotá, Colombia: Legis Editores S.A.

González Navarro, A. L. (2011). La prueba en el Sistema Penal Acusatorio. Bogotá, Colombia: Editorial Leyer.

López Medina, D. (2006). Interpretación constitucional. Bogotá, Colombia: Universidad Nacional de Colombia.

López Medina, D. (2009). El Derecho de los jueces. Bogotá, Colombia: Editorial Legis.

Sentencia C-591 (2005). Corte Constitucional de Colombia. Magistrada ponente: Clara Inés Vargas Hernández.

Sentencia (2005, junio 12). Corte Suprema de Justicia. Sala de Casación Penal. Radicado $\mathrm{N}^{\circ}$. 14464. Magistrado ponente: Edgar Lombana Trujiillo.

Sentencia (2006, marzo 30). Corte Suprema de Justicia. Sala de Casación Penal. Radicado $\mathrm{N}^{\circ}$. 24468. Magistrado ponente: Edgar Lombana Trujillo.

Sentencia C-396 (2007). Corte Constitucional de Colombia. Magistrado ponente: Marco Gerardo Monroy Cabra.

Sentencia (2010, mayo 19). Corte Suprema de Justicia. Sala de Casación Penal. Radicado $N^{\circ}$. 31091. Magistrado ponente: Julio Enrique Socha Salamanca.

Sentencia (2015, agosto 5). Corte Suprema de Justicia. Sala de Casación Penal. Radicado $\mathrm{N}^{\circ}$. 45.699. Magistrado ponente: Eyder Patiño Cabrera.

Sentencia (2016, abril 6). Corte Suprema de Justicia. Sala de Casación Penal. Radicado $\mathrm{N}^{\circ}$. 47.212. Magistrado ponente: Eyder Patiño Cabrera.

Sentencia (2016, mayo 25). Corte Suprema de Justicia. Sala de Casación Penal. Radicado $N^{\circ} 43837$. Magistrado ponente: Gustavo Enrique Malo Fernández. 